\title{
Influence of Controlled Drainage on the Groundwater Nitrogen and Phosphorus Concentration at Jointing-Booting Stage of Wheat
}

\author{
Jin-tao Cui, Guang-cheng Shao, Shuang-en Yu, and Xi Cheng \\ Key Laboratory of Efficient Irrigation-Drainage and Agricultural Soil-Water Environment in Southern China, Ministry of Education, \\ College of Water Conservancy and Hydropower Engineering, Hohai University, Nanjing 210098, China
}

Correspondence should be addressed to Guang-cheng Shao; sgcln@126.com

Received 17 March 2016; Revised 26 May 2016; Accepted 13 July 2016

Academic Editor: Jun Wu

Copyright (C) 2016 Jin-tao Cui et al. This is an open access article distributed under the Creative Commons Attribution License, which permits unrestricted use, distribution, and reproduction in any medium, provided the original work is properly cited.

\begin{abstract}
The effect of controlled drainage on nitrogen $(\mathrm{N})$ and phosphorus $(\mathrm{P})$ emission at jointing-booting stage of winter wheat was studied in 2007-2008. The conventional subsurface drainage was taken as the control (T5). The groundwater depth was naturally drained to $400 \mathrm{~mm}$ and $800 \mathrm{~mm}$ below the soil surface within 3 days at the jointing-booting stage, after the water level was kept at $100 \mathrm{~mm}$ for 1 day $(\mathrm{T} 1, \mathrm{~T} 2)$ and 3 days $(\mathrm{T} 3, \mathrm{~T} 4)$ from the soil surface. Results showed that controlled drainage could significantly reduce the concentration of $\mathrm{P}$ and $\mathrm{N}$ in groundwater. Compared to $\mathrm{T} 5$, the four controlled treatments could significantly decrease the concentration of TP, $\mathrm{NH}_{4}{ }^{+}-\mathrm{N}$, and $\mathrm{NO}_{3}{ }^{-}-\mathrm{N}$. The highest concentration reduction for TP and $\mathrm{NO}_{3}{ }^{-}-\mathrm{N}$ was observed under T4 and $\mathrm{Tl}$, which reached $64.9 \%$ and $73.2 \%$, respectively. As for the concentration of $\mathrm{NH}_{4}{ }^{+}-\mathrm{N}$, the highest reduction was obtained under T2. The change of TP concentration was significantly affected by the interaction of submergence time and drain depth, while the influence of controlled drainage on $\mathrm{NH}_{4}{ }^{+}-\mathrm{N}$ concentration was not significant. The submergence time, drain depth, and the interaction of submergence time and drain depth had significant effect on the change of concentration of $\mathrm{NO}_{3}{ }^{-}-\mathrm{N}$.
\end{abstract}

\section{Introduction}

Since the irrational irrigation and drainage and excessive fertilization on the farmland, large amounts of nitrogen and phosphorus had been lost from farmland by ways of runoff and leakage. This is an important reason for the eutrophication of water body in recent years [1-4]. In southern China, winter wheat often receives high amount of $\mathrm{N}$ fertilizer which combined with shallow root system and drainage poses a high risk of $\mathrm{N}$ leaching losses. High $\mathrm{N}$ leaching losses from wheat have been reported in several studies from China [5]. The soils used for winter wheat in southern China show low P sorption capacity and shallow groundwater level; P leaching losses from wheat may also be high. Drainage is an important measure to allow timely field operation and protect wheat field from waterlogging. However, irrational drainage shortens the residence time of water in the biologically active unsaturated zone and substantially alters the water regime.
Attempts to reduce nutrient losses in drainage water have led to the development of controlled drainage (CD). Controlled drainage aimed to maintain a higher depth of water and captured more drainage water than traditional drainage in the field $[6,7]$. Results showed that controlled drainage could reduce drainage quantity [8]. Moreover, the concentration of $\mathrm{N}$ and $\mathrm{P}$ in drainage water could be decreased, especially in surface runoff. These studies further stressed the importance of controlled drainage in decreasing the loss of $\mathrm{N}$ and $\mathrm{P}$ from field $[9,10]$. Yin et al. [11-13] showed that surface controlled drainage measures could effectively reduce the concentration of nitrogen in the drainage and the drainage outflow volumes. At the same time, the multiobjective controlled drainage model was developed for storm drainage and reducing nitrogen and phosphorus loss [14]. Qiao et al. [15] showed that, under shallow-irrigation and deep-sluice model, the drainage flow of controlled drainage decreases $7.6 \%$ compared with uncontrolled drainage. Wesström and Messing [10] reported 


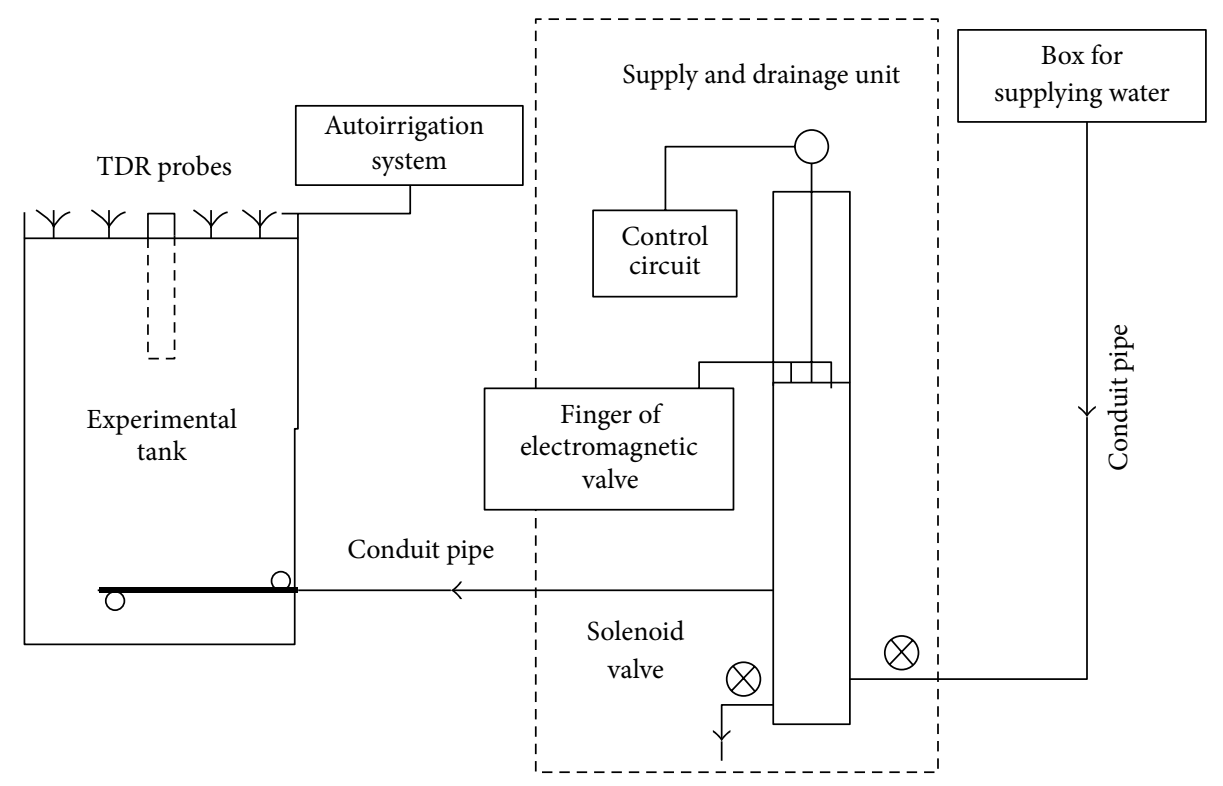

FIgURE 1: Schematic diagram of the experimental setup placed in the tank.

79\% and 94\% reductions in drain outflows for successive years following controlled drainage implementation. Field experiment and modeling with DRAINMOD by Wang et al. [16] showed that the proposed model was effective for predicting the surface runoff, subsurface drainage, and nitrate loss.

The researches on the changes of $\mathrm{N}$ and $\mathrm{P}$ concentration in groundwater of wheat field which focus on the whole growth period have been reported frequently [17-19]. However, as for one growth stage, especially the jointing-booting stage, which is a critical period of wheat growth, the related research is rare. Here, we presented field measurements of $\mathrm{N}$ and $\mathrm{P}$ from the groundwater of wheat field under controlled drainage in southern China in 2007-2008. The main objective is to gain an insight into the concentration of $\mathrm{P}$ and $\mathrm{N}$ change under controlled drainage at the jointing-booting stage. Besides, controlled drainage whether to further take advantage of the interactive effect of submergence duration combined with drainage depth should be confirmed and further studied. Therefore, this study can provide basis for reasonable drainage scheme about winter wheat field and an effective option for mitigating environmental pollution.

\section{Materials and Methods}

2.1. Experimental Site and the Soil Properties. The experiment was carried out in specially designed experimental tanks at the Key Laboratory of Efficient Irrigation-Drainage and Agricultural Soil-Water Environment in Southern China, Ministry of Education $\left(31^{\circ} 57 / \mathrm{N}, 118^{\circ} 50 / \mathrm{E}\right)$, during the winter wheat growing seasons of 2007-2008. The study area has a subtropical monsoon climate with average annual air temperature of $15.4 \circ \mathrm{C}$ and mean annual evaporation of $900 \mathrm{~mm}$. The average annual precipitation is $1,051 \mathrm{~mm}$, where more than $60 \%$ of precipitation falls in the rainy season and the precipitation is concentrated in the months of MaySeptember. The frost-free period is 220 days per year.

There were 15 fixed tanks, and each of them was $2 \mathrm{~m}$ wide, $2.5 \mathrm{~m}$ long, and $2 \mathrm{~m}$ high container constructed from concrete block and sealed with a waterproof paint. Figure 1 was the schematic diagram of a setup for maintaining ponding water depth. Groundwater level was changed by raising or lowering the height of the finger of electromagnetic valve relative to the bottom of each tank. When ponding water depth lowered to lower limit of designed water level, irrigation water was added until water table reached upper limit of designed water level with autoirrigation system (vice versa).

The soil texture of the experimental tanks in the plowed layer was clay, with $\mathrm{pH}$ value of 7.78 , organic matter of $2.40 \%$, total phosphorus of $0.32 \mathrm{~g} \cdot \mathrm{kg}^{-1}$, available phosphorus of $53.63 \mathrm{mg} \cdot \mathrm{kg}^{-1}$, total nitrogen of $0.67 \mathrm{~g} \cdot \mathrm{kg}^{-1}$, and available nitrogen of $12.5 \mathrm{mg} \cdot \mathrm{kg}^{-1}$. The saturated soil water contents $\left(\mathrm{m} \cdot \mathrm{m}^{-1}\right)$ for the layer of $0-30 \mathrm{~cm}$ were $30.4 \%$, and field waterholding rate was $26.5 \%$.

2.2. Experimental Design and Management. Five treatments were used to evaluate the effect of controlled drainage at jointing-booting stage on the change of $\mathrm{N}$ and $\mathrm{P}$ concentration, as shown in Table 1. The control (T5) was the conventional subsurface drainage, where the relative soil water content was maintained at $70-80 \%$ and the groundwater level was kept below $-600 \mathrm{~mm}$ at the tillering stage, $-800 \mathrm{~mm}$ at the jointing-booting stage, and $-1,000 \mathrm{~mm}$ at the onset of flowering. The water depth of control treatments was kept $100 \mathrm{~mm}$ from the soil surface at other treatments. The water layer above the soil was maintained for 1 day, and then it was drained to $-400 \mathrm{~mm}$ (T1) and $-800 \mathrm{~mm}$ (T2) below the surface within 3 days at the jointing-booting stage. The water layer above the soil was maintained for 3 days, and then it was drained to $-400 \mathrm{~mm}$ (T3) and $-800 \mathrm{~mm}$ (T4) below the 
TABLE 1: Design of controlled drainage scheduling.

\begin{tabular}{|c|c|c|c|c|}
\hline Treatments & Tillering stage $/ \mathrm{mm}$ & Jointing-booting stage & Panicle initiation stage $/ \mathrm{mm}$ & Milky stage $/ \mathrm{mm}$ \\
\hline $\mathrm{T} 1$ & $\leq-600$ & $100 \mathrm{~mm}(1 \mathrm{~d})(3 \mathrm{~d}-400)$ & $\leq-1000$ & $\leq-1000$ \\
\hline $\mathrm{T} 2$ & $\leq-600$ & $100 \mathrm{~mm}(1 \mathrm{~d})(3 \mathrm{~d}-800)$ & $\leq-1000$ & $\leq-1000$ \\
\hline $\mathrm{T} 3$ & $\leq-600$ & $100 \mathrm{~mm}(3 \mathrm{~d})(3 \mathrm{~d}-400)$ & $\leq-1000$ & $\leq-1000$ \\
\hline $\mathrm{T} 4$ & $\leq-600$ & $100 \mathrm{~mm}(3 \mathrm{~d})(3 \mathrm{~d}-800)$ & $\leq-1000$ & $\leq-1000$ \\
\hline T5 & $\leq-600$ & $\leq-800$ & $\leq-1000$ & $\leq-1000$ \\
\hline
\end{tabular}

Note: $I \mathrm{~mm}(K \mathrm{~d})(M \mathrm{~d}-J \mathrm{~mm}): I \mathrm{~mm}$ fixed water level was kept with duration of $K$ day at Jointing-booting stages from the soil surface and drained to $-J$ $\mathrm{mm}$ in $M$ days. $<-N \mathrm{~mm}:-N \mathrm{~mm}$ was the upper limit of groundwater level, if groundwater level exceeded the value and drainage would be conducted. Tl, $\mathrm{T} 2$, T3, and T4 denote different controlled treatments at jointing-booting stage; T5 as the control indicates conventional subsurface drainage.

TABLE 2: Division of growth stages of winter wheat in 2007-2008.

\begin{tabular}{lcccc}
\hline Stages & Tillering stage & Jointing-booting stage & Panicle initiation stage & Milky stage \\
\hline Starting date & February 11 & March 26 & April 17 & May 1 \\
End date & March 25 & April 16 & April 30 & May 25 \\
\hline
\end{tabular}

surface within 3 days at the jointing-booting stage. Except at the jointing-booting stage, the water level of treatments was the same as $\mathrm{T} 5$ at other growth stages. These treatments were arranged in a randomized complete block design with three replications and means were compared with a Least Squares Means procedure.

Yangmai 14, hybrid wheat currently used in local production, was grown in the experiment tanks at the rate of $150 \mathrm{~kg} \cdot \mathrm{ha}^{-1}$ on 12 November in 2007. Applications of fertilizer $\left(\mathrm{N}: \mathrm{P}_{2} \mathrm{O}_{5}: \mathrm{K}_{2} \mathrm{O}, 15: 10: 15\right)$ at the rate of $1500 \mathrm{~kg} \cdot \mathrm{ha}^{-1}$ in the form of compound fertilizer were applied in tanks evenly. Each treatment includes the same agronomic measures except irrigation and drainage.

According to the growth characteristics of winter wheat and combined with observations of physiological and ecological in the testing process, the growth stages of wheat were divided into four stages (Table 2).

2.3. Sample Collection and Measurement. Water treatment was started on April 3 in 2008. During the controlled drainage period, water samples were collected in the polyethylene bottle for four times, at the beginning and end of the submergence and drainage. The subsurface water was collected by the underground drainage pipe. The sampled water was analyzed for total phosphorus (TP), ammonium nitrogen $\left(\mathrm{NH}_{4}{ }^{+}-\mathrm{N}\right)$, and nitrate nitrogen $\left(\mathrm{NO}_{3}{ }^{-}-\mathrm{N}\right)$ through the use of a Shimadzu UV-2800 spectrophotometer. Spectrophotometric determination of molybdenum and antimony with potassium sulfa was used to measure the concentration of total phosphorus (TP). In addition, spectrophotometric determination of the reagent of flocculation and precipitation and the ultraviolet spectrophotometry were used to analyze ammonium nitrogen $\left(\mathrm{NH}_{4}{ }^{+}-\mathrm{N}\right)$ and nitrate nitrogen $\left(\mathrm{NO}_{3}{ }^{-}\right.$$\mathrm{N})$ content in water test, respectively.

2.4. Statistical Analysis. Data were analyzed using multivariate analysis of variance (MANOVA) procedure of SPSS software Version 22.0. Treatment means were separated by least significant difference (LSD) test at the 0.05 probability level.

\section{Results}

3.1. The Change of Concentration of TP. Compared to T5, the CD treatments had significant impacts on the change of the concentration of TP $(p \leq 0.05)$. The reduction of concentration of TP under T4 registered the highest percentage $(64.9 \%)$, while the lowest $(4.6 \%)$ was T5 (Figure 2). The average change of TP concentration under T1 and T3 (37.2\%) was closed to the average value under $\mathrm{T} 2$ and $\mathrm{T} 4$ (39.5\%). Similarly, compared with the average change value of T1 and T2, the average value of T3 and T4 was high 9\%. Furthermore, although the same fixed water level under T1 and $\mathrm{T} 2$ was kept for same day, the change of concentration of TP under T1 was almost $400 \%$ higher than T2 due to different drainage depth, and the concentration change decreased as the depth increases. On the contrary, the change of percentage increased as the depth increases under T3 and T4. The MANOVA indicated submergence duration and drainage depth had insignificant effect on the change of concentration of total phosphorus; however, the interaction of submergence duration and drainage depth had significant effect (Table 3).

3.2. The Change of Concentration of $\mathrm{NH}_{4}^{+}-\mathrm{N}$. Figure 3 showed the change of concentration of $\mathrm{NH}_{4}{ }^{+}-\mathrm{N}$ from the beginning to the end of five treatments. Submergence duration and drainage depth both had significant effect on the change of concentration of $\mathrm{NH}_{4}{ }^{+}-\mathrm{N}$ (Table 3). Compared with the control, $\mathrm{CD}$ treatments had significant impacts on the concentration of $\mathrm{NH}_{4}{ }^{+}-\mathrm{N}(p \leq 0.05)$. The $\mathrm{NH}_{4}{ }^{+}-\mathrm{N}$ concentration for $\mathrm{T} 1, \mathrm{~T} 2, \mathrm{~T} 3, \mathrm{~T} 4$, and $\mathrm{T} 5$ was reduced by $12.9 \%, 23.1 \%, 8.1 \%, 20.6 \%$, and $2.9 \%$, respectively. Table 3 indicated that the interaction between submergence duration and drainage depth did not significantly affect the change of the concentration of $\mathrm{NH}_{4}{ }^{+}-\mathrm{N}(p \leq 0.05)$. 


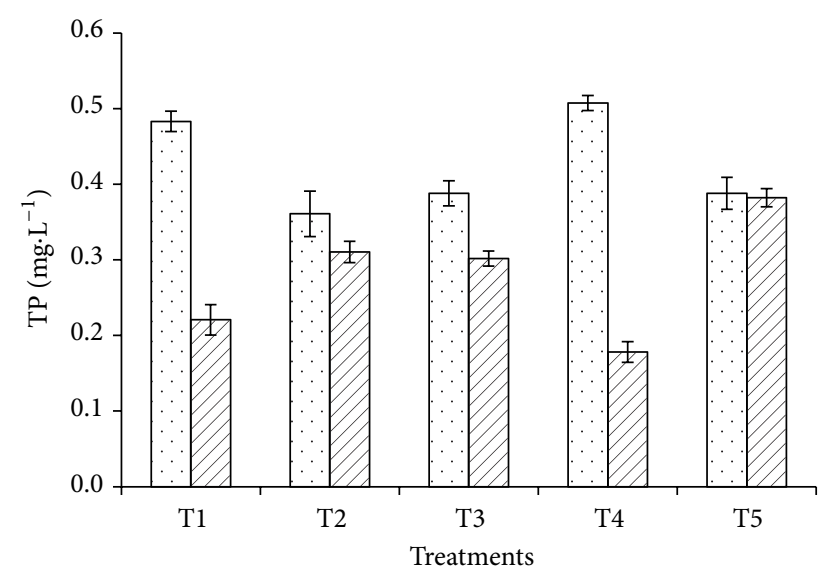

$\square$ Initial concentration

$\square$ Final concentration

FIGURE 2: The change of the concentration of TP under controlled drainage at jointing-booting stage. The initial and final concentrations are the TP concentration in groundwater at the beginning of submergence and end of drainage, respectively. Vertical bars represent \pm standard error (SE) of the mean.

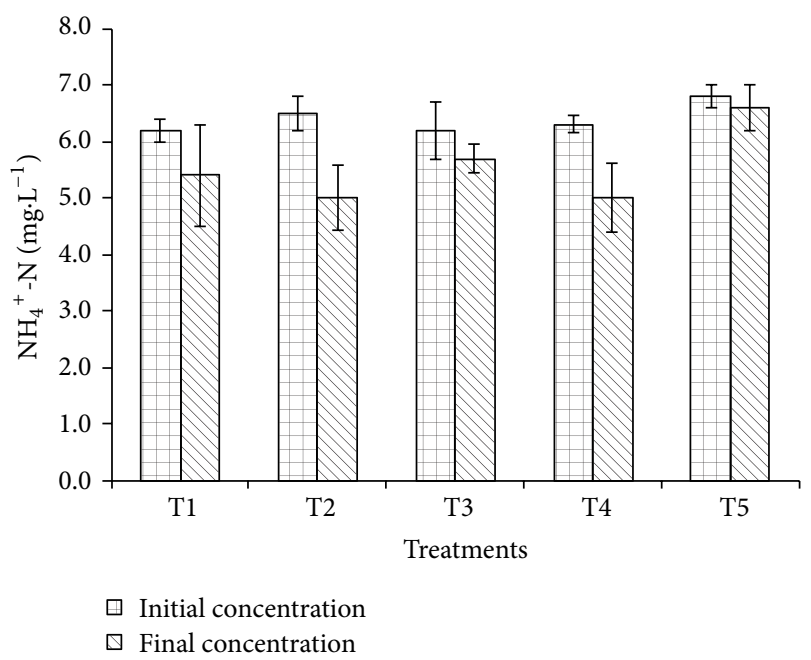

FIGURE 3: The change of the concentration of $\mathrm{NH}_{4}{ }^{+}-\mathrm{N}$ under controlled drainage at jointing-booting stage. The initial and final concentrations are the $\mathrm{NH}_{4}{ }^{+}-\mathrm{N}$ concentration in groundwater at the beginning of submergence and end of drainage, respectively. Vertical bars represent \pm standard error (SE) of the mean.

TABLE 3: MANOVA results for the change of concentration of TP, $\mathrm{NH}_{4}{ }^{+}-\mathrm{N}$, and $\mathrm{NO}_{3}{ }^{-}-\mathrm{N}$.

\begin{tabular}{lccc}
\hline MANOVA results ( $p$ values) & $\mathrm{TP}$ & $\mathrm{NH}_{4}{ }^{+}-\mathrm{N}$ & $\mathrm{NO}_{3}{ }^{-}-\mathrm{N}$ \\
\hline Submergence time & $0.073 \mathrm{~ns}$ & $0.008^{*}$ & $0.028^{*}$ \\
Drainage depth & $0.092 \mathrm{~ns}$ & $0.000^{*}$ & $0.002^{*}$ \\
Submergence time $\times$ drainage depth & $0.000^{*}$ & $0.354 \mathrm{~ns}$ & $0.000^{*}$ \\
\hline
\end{tabular}

Note: the values of $\mathrm{TP}, \mathrm{NH}_{4}{ }^{+}-\mathrm{N}$, and $\mathrm{NO}_{3}{ }^{-}-\mathrm{N}$ concentration are means of 3 replications. Significant differences for submergence duration, drainage depth, and submergence duration $\times$ drainage depth are indicated with asterisks $(*)$ for $\alpha<0.05$; ns: not significant.

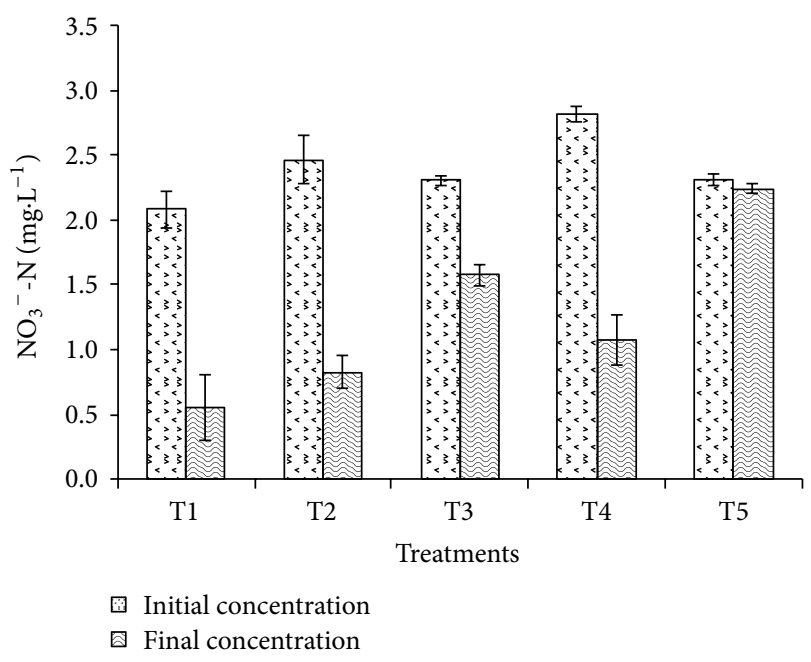

Figure 4: The change of the concentration of $\mathrm{NO}_{3}{ }^{-} \mathrm{N}$ under controlled drainage at jointing-booting stage. The initial and final concentrations are the $\mathrm{NO}_{3}{ }^{-}-\mathrm{N}$ concentration in groundwater at the beginning of submergence and end of drainage, respectively. Vertical bars represent \pm standard error (SE) of the mean.

3.3. The Change of Concentration of $\mathrm{NO}_{3}{ }^{-}-\mathrm{N}$. The change of the concentration of the $\mathrm{NO}_{3}{ }^{-}-\mathrm{N}$ in groundwater under $\mathrm{CD}$ treatments was shown in Figure 4. The concentration of $\mathrm{NO}_{3}{ }^{-}-\mathrm{N}$ under $\mathrm{CD}$ treatments declined after submergence. There are significant differences between CD treatments and the control for the decreased percentage of concentration of the $\mathrm{NO}_{3}{ }^{-}-\mathrm{N}$. It indicated that the combination of submergence duration and drainage depth both had a significant effect on the concentration of the $\mathrm{NO}_{3}{ }^{-}-\mathrm{N}(p \leq 0.05)$. The decreased percentage of the concentration $\mathrm{NO}_{3}{ }^{-}-\mathrm{N}$ under T1 reached the maximum (73.2\%) among five treatments, while the smallest decreased percentage (31.6\%) was obtained under T3. As was seen from Table 3, submergence duration, drainage depth, and the interaction between submergence duration and drainage depth had significant influence on the change of concentration of $\mathrm{NO}_{3}{ }^{-}-\mathrm{N}$.

\section{Discussion}

The jointing-booting stage was a key period during the period of winter wheat growth, because the dry matter accumulation mainly occurred at this stage $[20,21]$. The vegetative and reproductive growth of wheat developed simultaneously, and then physiological metabolism was rapid at this stage, which led to the great demand for nitrogen and phosphorus. In this experiment, the concentration of $\mathrm{N}$ and $\mathrm{P}$ in underground water was obviously decreased by controlled treatments at jointing-booting stage. The decrease of TP concentration in groundwater was mainly through the fixation of soil particles and the absorption of wheat during the submergence [22]. The absorption was affected by submergence duration and the groundwater depth, which led to the reduction of TP concentration among the controlled treatments. This was consistent with the research of Yin et al. [23], in which the TP 
concentration in groundwater was significantly decreased by almost $50 \%$ under the condition of controlled drainage.

The major nitrogen treatment mechanisms of wheat included sedimentation, chemical adsorption, microbial interactions with nitrogen, and plant uptake [24-27]. The sedimentation and chemical adsorption were both dependent on duration and soil style. As for the microorganisms, the biological nitrogen transition included a two-opposite process: nitrification and denitrification. Nitrification implied a chemolithoautotrophic oxidation of ammonia to nitrate under strict aerobic conditions. The nitrification process highly demanded oxygen. Under controlled drainage condition, the biological denitrification mechanism made use of nitrate as the terminal electron acceptor in low-oxygen environments [28]. This led to the result that the change of concentration of $\mathrm{NO}_{3}{ }^{-} \mathrm{N}$ was higher than that of $\mathrm{NH}_{4}{ }^{+}-\mathrm{N}$. As was shown in Figures 3 and $4, \mathrm{NH}_{4}{ }^{+}-\mathrm{N}$ was the major component of N in runoff water after submergence. Similarly, Shao et al. [27] also found that the concentration of $\mathrm{NH}_{4}{ }^{+}-$ $\mathrm{N}$ was more than six times as much as $\mathrm{NO}_{3}{ }^{-}-\mathrm{N}$ during the submergence.

The growth condition of wheat was an important factor in the reduction of nitrogen in groundwater. The winter wheat was more influenced by $\mathrm{NO}_{3}{ }^{-}-\mathrm{N}$ than $\mathrm{NH}_{4}{ }^{+}-\mathrm{N}$ [29], which was another reason why the concentration of $\mathrm{NO}_{3}{ }^{-}$$\mathrm{N}$ was lower than that of $\mathrm{NH}_{4}{ }^{+}-\mathrm{N}$. When shorter duration of submergence was kept, the concentration of $\mathrm{NH}_{4}{ }^{+}-\mathrm{N}$ and $\mathrm{NO}_{3}{ }^{-}-\mathrm{N}$ tended to favor salient reduction. This was because of the stronger root respiration which affected the absorption and utilization of nutrients [30,31]. This also explained why the emission reduction was lower under T3 than the other $\mathrm{CD}$ treatments. Similar results were also reported under the controlled drainage condition in southern China [32].

This study only investigated the change of $\mathrm{TP}, \mathrm{NH}_{4}{ }^{+}$$\mathrm{N}$, and $\mathrm{NO}_{3}{ }^{-}-\mathrm{N}$ concentration at joint booting stage of wheat, under the controlled drainage treatments. It did not investigate the effect of controlled drainage on the amount of water discharge and concentration varying with time after submergence withdrawal. More research needs to be carried out in the future to define these relationships.

\section{Conclusion}

In southern China, traditional drainage might be considered as an efficient mean to rapidly eliminate excess water on the farmland. Nevertheless, this treatment might lead to large amounts of nitrogen and phosphorus loss from farmland and exacerbating water eutrophication. Controlled drainage as an effective drainage method could significantly reduce the concentration of nitrate-nitrogen, ammonium nitrogen, and total phosphorus in groundwater wheat field. Compared with the conventional subsurface drainage, controlled drainage reduced highest the concentration of $\mathrm{TP}, \mathrm{NH}_{4}{ }^{+} \mathrm{N}$, and $\mathrm{NO}_{3}{ }^{-}-\mathrm{N}$ losses in groundwater by $64.9 \%$ (T4), $23.1 \%$ (T2), and $73.2 \%$ (T1), respectively. Results of MAOVA for the change of TP concentration showed that the interaction of submergence time and drain depth was significant, while the influence of controlled drainage on $\mathrm{NH}_{4}^{+}-\mathrm{N}$ concentration was not significant. The submergence time, drain depth, and the interaction of submergence time and drain depth had significant effect on the change of concentration of $\mathrm{NO}_{3}{ }^{-}$$\mathrm{N}$. Therefore, the intensity of controlled drainage must be considered particularly, including submergence duration and drainage depth, in order to obtain the greater reduction effect and the normal growth of wheat at the later stage.

\section{Competing Interests}

The authors declare that there is no conflict of interests regarding the publication of this paper.

\section{Acknowledgments}

This work was funded by Key Program granted by the National Nature \& Science Foundation of China (nos. 51479063, 51279059, and 41271236) and supported by the program of "the Fundamental Research Funds for the Central Universities" (2015B14714) and the project of "the Priority Academic Program Development of Jiangsu Higher Education Institutions" and "Jiang Su Qing Lan."

\section{References}

[1] J. S. Kim, S. Y. Oh, and K. Y. Oh, "Nutrient runoff from a Korean rice paddy watershed during multiple storm events in the growing season," Journal of Hydrology, vol. 327, no. 1-2, pp. 128-139, 2006.

[2] A. Chhabra, K. R. Manjunath, and S. Panigrahy, "Non-point source pollution in Indian agriculture: estimation of nitrogen losses from rice crop using remote sensing and GIS," International Journal of Applied Earth Observation and Geoinformation, vol. 12, no. 3, pp. 190-200, 2010.

[3] S. Z. Peng, S. H. Yang, J. Z. Xu, and H. Z. Gao, "Field experiments on greenhouse gas emissions and nitrogen and phosphorus losses from rice paddy with efficient irrigation and drainage management," Science China Technological Sciences, vol. 54, no. 6, pp. 1581-1587, 2011 (Chinese).

[4] S.-L. Wang, "Advancement of study on farmland drainage technology based on water environment protection," Journal of Hydraulic Engineering, vol. 41, no. 6, pp. 697-702, 2010.

[5] G. J. Chen, Y. T. Lu, L. K. Cao, and D. D. Zhang, "Testing-hole on the Nitrogen leaching loss in the winter wheat," Journal of Agro-Environment science, vol. 23, no. 3, pp. 494-498, 2004.

[6] V. Luederitz, E. Eckert, M. Lange-Weber, A. Lange, and R. M. Gersberg, "Nutrient removal efficiency and resource economics of vertical flow and horizontal flow constructed wetlands," Ecological Engineering, vol. 18, no. 2, pp. 157-171, 2001.

[7] H. Li, X. Liang, Y. Chen, G. Tian, and Z. Zhang, "Ammonia volatilization from urea in rice fields with zero-drainage water management," Agricultural Water Management, vol. 95, no. 8, pp. 887-894, 2008.

[8] I. Wesström, I. Messing, H. Linnér, and J. Lindström, "Controlled drainage-effects on drain outflow and water quality," Agricultural Water Management, vol. 47, no. 2, pp. 85-100, 2001.

[9] J. E. Ayars, E. W. Christen, and J. W. Hornbuckle, "Controlled drainage for improved water management in arid regions irrigated agriculture," Agricultural Water Management, vol. 86, no. 1-2, pp. 128-139, 2006. 
[10] I. Wesström and I. Messing, "Effects of controlled drainage on $\mathrm{N}$ and $\mathrm{P}$ losses and $\mathrm{N}$ dynamics in a loamy sand with spring crops," Agricultural Water Management, vol. 87, no. 3, pp. 229240, 2007.

[11] X. G. Guo, Z. Y. Zhang, and G. X. Yin, "Effect of controlled drainage on loss of nitrogen and phosphorous from paddy field," Journal of Shanghai Jiaotong University (Agricultural Science), no. 3, pp. 307-310, 2006 (Chinese).

[12] G. X. Yin, Z. Y. Zhang, X. P. Guo, and G. C. Shao, "Experimental study on effect of controlled drainage from ground surface on concentration and discharge of nitrogen," Journal of Hohai University (Natural Sciences), no. 1, pp. 21-24, 2006 (Chinese).

[13] G.-X. Yin, Z.-Y. Zhang, X.-P. Guo, and G.-C. Shao, "Effect of drainage controlling devices on nitrogen losses in surface runoff of farmland," Journal of Hydraulic Engineering, vol. 37, no. 8, pp. 926-931, 2006 (Chinese).

[14] G. X. Yin, Z. Y. Zhang, G. H. Zhang, and X. P. Guo, "Multiobjective controlled drainage model based on particle swarm optimized algorithm," Transactions of the Chinese Society of Agricultural Engineering, vol. 25, no. 3, pp. 6-9, 2009 (Chinese).

[15] X. Qiao, D.-G. Shao, H.-H. Liu, and J.-G. Yuan, "Study on the moving and transforming law of $\mathrm{N}$ and $\mathrm{P}$ under watersaving irrigation and controlled drainage," Journal of Hydraulic Engineering, vol. 42, no. 7, pp. 862-868, 2011 (Chinese).

[16] S. L. Wang, S. O. Prasher, Y. C. Chieh, and C. S. Tan, "Field evaluation of DRAINMOD-N model for surface runoff subsurface drainage and nitrogen loss," Journal of Hydraulic Engineering, vol. 35, no. 9, pp. 111-117, 2004 (Chinese).

[17] J. He, Y. Cui, J. Wang, and W. Shi, "Experiments on nitrogen and phosphorus losses from paddy fields under different scales," Transactions of the Chinese Society of Agricultural Engineering, vol. 26, no. 10, pp. 56-62, 2010 (Chinese).

[18] G. C. Shao, S. E. Yu, N. L. Liu, and L. B. Xu, "Study on continuous days of water logging and excessive soil water as drainage index of wheat," Transactions of the Chinese Society of Agricultural Engineering, vol. 26, no. 8, pp. 56-60, 2010.

[19] Z. L. Chen, J. Cheng, P. Liu, X. C. Peng, Z. C. Xu, and Z. F. $\mathrm{Wu}$, "An experiment on influence of storm on nitrogen loss and phosphorus loss under different land use in river basin," Journal of Soil and Water Conservation, no. 5, pp. 30-33, 2008.

[20] X. Liu, L. Sui, Y. Huang, C. Geng, and B. Yin, "Physiological and visible injury responses in different growth stages of winter wheat to ozone stress and the protection of spermidine," Atmospheric Pollution Research, vol. 6, no. 4, pp. 596-604, 2015.

[21] P. R. Ryan, M. Liao, E. Delhaize et al., "Early vigour improves phosphate uptake in wheat," Journal of Experimental Botany, vol. 66, no. 22, pp. 7089-7100, 2015.

[22] C. R. Yates and S. O. Prasher, "Phosphorus reduction from agricultural runoff in a pilot-scale surface-flow constructed wetland," Ecological Engineering, vol. 35, no. 12, pp. 1693-1701, 2009.

[23] G. X. Yin, Z. Y. Zhan, and G. C. Shao, "Effects of controlled drainage from field surface on concentration of phosphor discharge," Advances in Science and Technology of Water Resources, vol. 26, no. 4, pp. 24-26, 2006 (Chinese).

[24] B.-J. Ni and Z. Yuan, "Recent advances in mathematical modeling of nitrous oxides emissions from wastewater treatment processes," Water Research, vol. 87, pp. 336-346, 2015.

[25] Q. X. Fang, R. W. Malone, L. Ma et al., "Modeling the effects of controlled drainage, $\mathrm{N}$ rate and weather on nitrate loss to subsurface drainage," Agricultural Water Management, vol. 103, pp. 150-161, 2012.
[26] S. Z. Peng, Y. P. He, S. H. Yang, and J. Z. Xu, "Effect of controlled irrigation and drainage on nitrogen leaching losses from paddy fields," Paddy and Water Environment, vol. 13, no. 4, pp. 303-312, 2014.

[27] G.-c. Shao, M.-h. Wang, S.-e. Yu, N. Liu, M.-h. Xiao, and M. Yuan, "Potential of controlled irrigation and drainage for reducing nitrogen emission from rice paddies in Southern China," Journal of Chemistry, vol. 2015, Article ID 913470, 9 pages, 2015.

[28] X. Hu, X. Shao, Y. Li, J. He, S. Lu, and Y. Qiu, "Effects of controlled and mid-gathering irrigation mode of paddy rice on the pollutants emission and reduction," Energy Procedia, vol. 16, pp. 907-914, 2012.

[29] Y. F. Miao, S. X. Li, X. F. Xu et al., "Responses of winter wheat to ammonium and nitrate nitrogen," Acta Pedologica Sinica, vol. 51, no. 3, pp. 564-574, 2014 (Chinese).

[30] X. Li, Y. S. Feng, and L. Boersma, "Partition of photosynthates between shoot and root in spring wheat (Triticum aestivum L.) as a function of soil water potential and root temperature," Plant and Soil, vol. 164, no. 1, pp. 43-50, 1994.

[31] M. D. Cramer and O. A. Lewis, "The Influence of $\mathrm{NO}_{3}{ }^{-}$and $\mathrm{NH}_{4}{ }^{+}$nutrition on the gas exchange characteristics of the roots of wheat (Triticum aestivum) and maize (zea mays) plants," Annals of Botany, vol. 72, no. 1, pp. 37-46, 1993.

[32] M.-H. Xiao, X.-J. Hu, and L.-L. Chu, "Experimental study on water-saving and emission-reduction effects of controlled drainage technology," Water Science and Engineering, vol. 8, no. 2, pp. 114-120, 2015. 

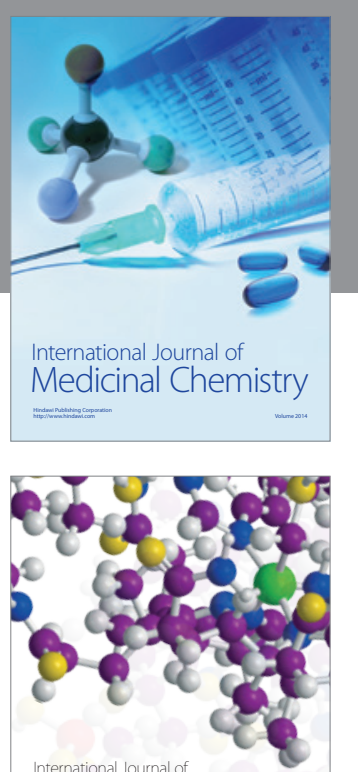

Carbohydrate Chemistry

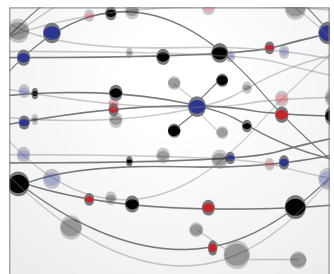

The Scientific World Journal
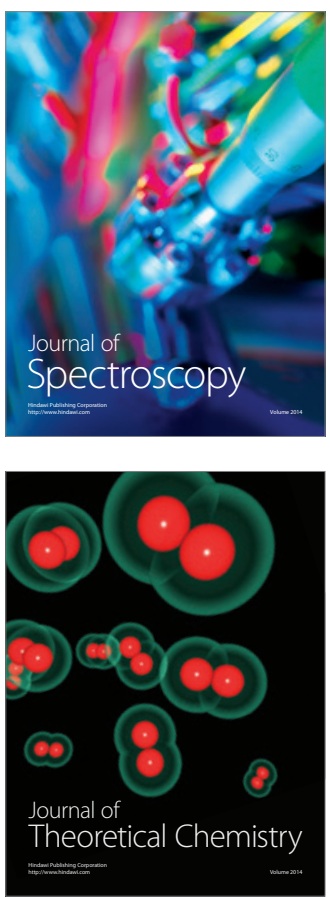
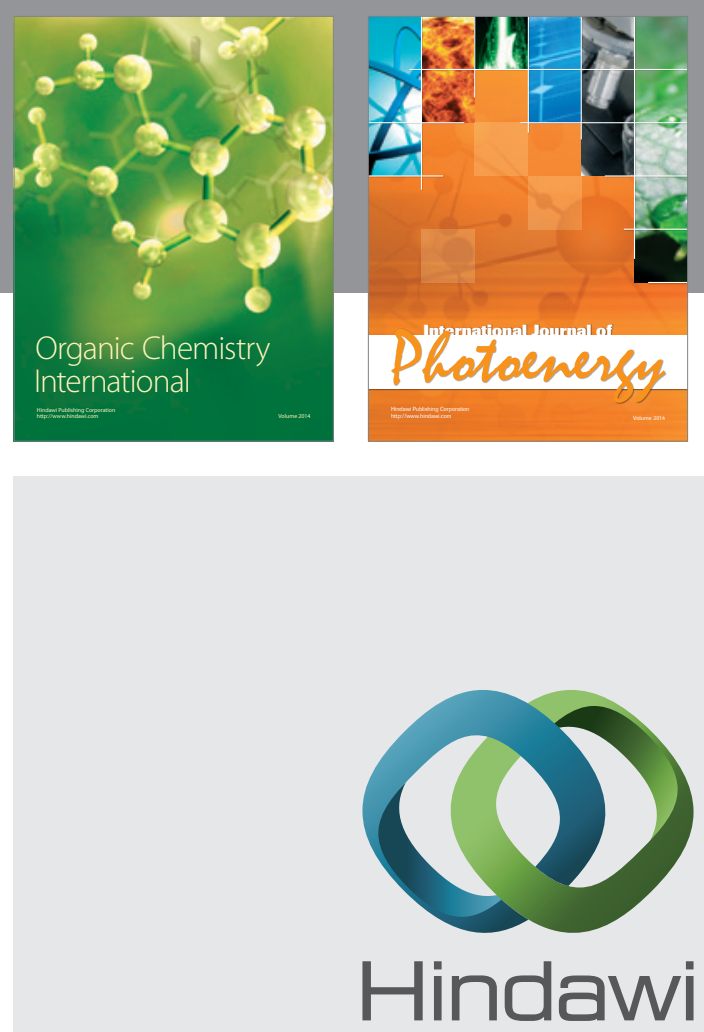

Submit your manuscripts at

http://www.hindawi.com

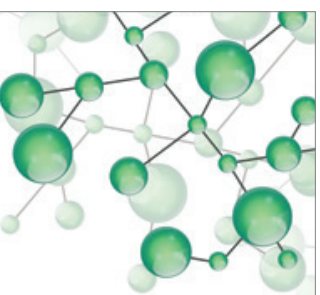

International Journal of

Inorganic Chemistry

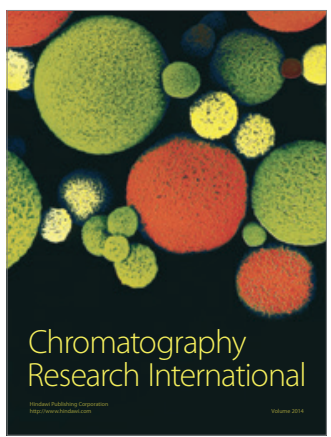

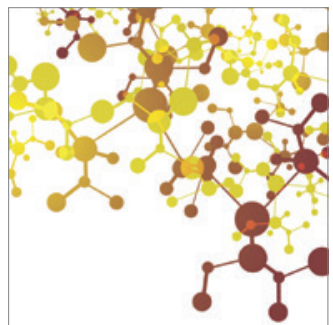

Applied Chemistry
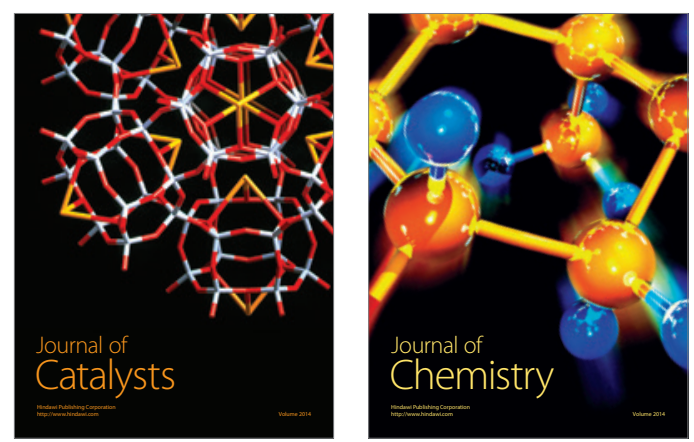
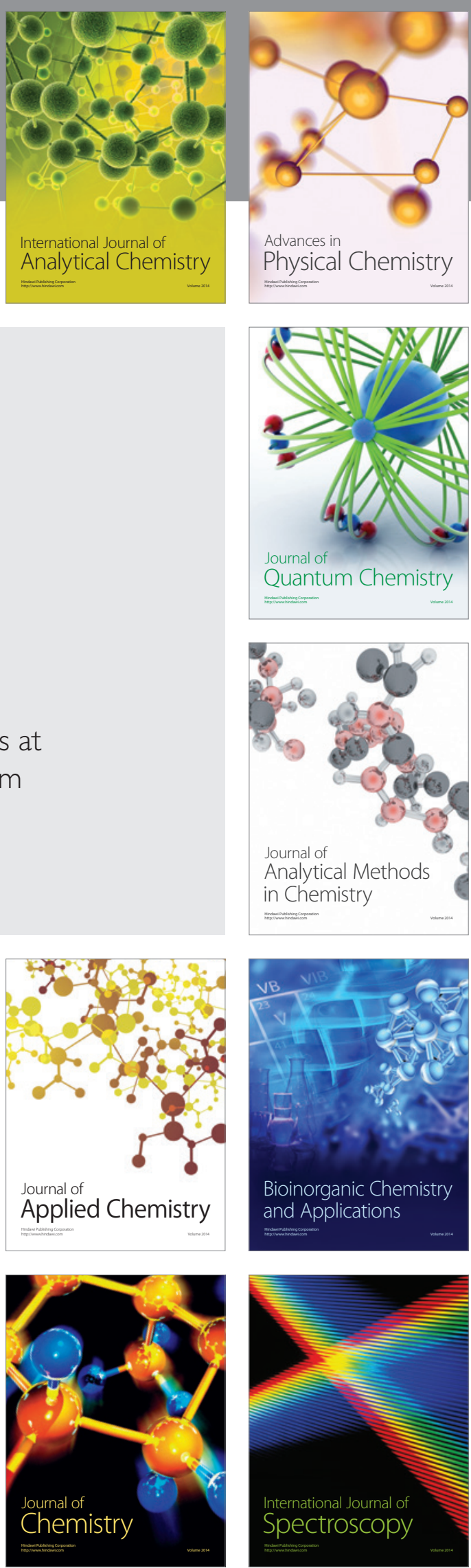